\title{
Development of Milk Chocolate Using Response Surface Methodology (RSM)
}

\author{
Singh Manpreet*, Chawla Rekha, Khatkar Sunil Kumar and Singh Sandeep \\ Dairy Technology Division, Guru Angad Dev Veterinary and Animal Sciences University \\ (GADVASU), Ludhiana, 141004, Punjab, India \\ *Corresponding author
}

\begin{abstract}
A B S T R A C T
Keywords

CCRD- Central Composite Rotatory Design, RSM Response Surface Methodology, Process Optimization, Sensory attributes.

Article Info

Accepted:

26 May 2017

Available Online:

10 June 2017

Milk chocolate was prepared with different levels of SMP, Sugar, C. Powder and C. Butter. The optimization was carried out using central composite rotatory design (CCRD) of response surface methodology, and the prepared product was examined for sensory and physical attributes. Cocoa powder had a significant effect on all responses at the linear level except flavour of milk chocolate. Cocoa butter affected the mouth feel, melting, sweetness and OA of the product at linear level, and SMP had a significant effect only on colour of milk chocolate at linear level. The sensory scores of prepared product for appearance, flavour, mouth feel, melting, texture, sweetness and overall acceptability varied from 7.12 to 8.1, 6.7 to $7.92,6$ to $8.25,6.6$ to $7.95,6.5$ to $8.05,6.3$ to 7.7 and 6.55 to 7.9 respectively. On the basis of sensory scores, product optimization was carried out aiming some minimum criteria of desired results. The results of the analysis showed that all the examined model solutions had significant influence on the different parameters indicating that the statistical model designed for these attributes fitted well in quadratic equation in all aspects of model efficiency check $\left(\mathrm{R}^{2}>0.80\right)$.
\end{abstract}

\section{Introduction}

Chocolate the food of god - is one of the most popular and common confectionary food product in the world and people enjoy its wonderful taste as it melts in the mouth. It is the product of cocoa and is made by mixing cocoa powder, sugar and milk powder in continuous fat phase, cocoa butter.

It can be either in the form of a liquid, paste or a block or used as a flavouring ingredient in different foods (Shahkhalili et al., 2000). Chocolate was introduced to Europe exclusively in Spain in the 16th and 17th century. The industrialization of chocolate production began in the beginning of the 20th century but even then it remained an adult luxury product, only for special occasions, celebrations or tender moments between friends (Jyothi, 2003). According to proportion of different ingredients used in preparation of chocolate, three main categories of chocolates are Dark, White and Milk chocolate. Milk powder is the major ingredient of milk chocolate and affects the sensory attributes of the chocolate and the rheological properties of chocolate fluid mass. 
In the manufacturing process of chocolate, solid particles are milled in refiner in order to form a chocolate into uniform mass and appropriate size distribution of solid particles. Among various ingredients, cocoa butter is central for enjoyment of its taste as it allows the chocolate solid at ambient temperature and melts it at body temperature. The oral liquefaction of chocolate is due to fat melting characteristic and this property of melting, influences the perception of flavour and mouth feel attributes. The market of chocolate is catching the increasing trend in the world and in India among all the confectionary food, chocolate ranks first (Jyothi, 2003). Some natural products have been claimed to successfully treat a wide range of disorders and chocolate is consider as one of them.

Chocolate is not only a product of blend of fat and sugar for pleasant taste but also have many beneficial and medicinal effects in the body. Chocolate is the rich source of flavonoids and polyphenols having high antioxidant activities (Pimsentel et al., 2010; Schinella et al., 2010 and Vanzani et al., 2011). The use of Theobroma cacao as a medicine in the past was ample, but there was no progress in medical uses and keeping this point in mind recent study have demonstrated a potential and unexpected role of cacao in "promoting health" of consumer and preventing from many diseases (Ding, 2006 ; Grassi, 2006). Many researchers have proven the beneficial health effect of chocolate on coronary vasculature (Allen et al., 2008); insulin secretion (Taubert et al., 2007); and endothelial function (Davison et al., 2008). Apart from these, animal studies have shown that the absorbed flavonoids directly interact with a number of cellular and molecular targets in the animal brain, exerting pronounced anti-oxidative effects and improving brain tissue and function in the regions mainly implicated in learning, memory, and cognition (Andrés-Lacueva et al., 2005; Passamonti et al., 2005; Vauzour et al., 2008).

\section{Materials and Methods}

The cocoa butter (continuous fat phase ingredient) for preparing the chocolate was procured from chocoville cocoa butter, Indore. Skim milk powder was procured from The Punjab State Cooperative Milk Producers Federation Limited available under the brand name Verka. Cocoa powder that has been used in milk chocolate preparation was procured from-Hershey's cocoa, Mumbai, and Icing sugar of good quality was procured from the local market of Ludhiana. To prepare smooth texture of chocolate, SMP was regrinded in cyclotech, for reducing the particle size diameter of skim milk powder from initial particle size 100-120 micron to final particle size 20-25 micron. Planetary mixer procured from Orange Foodstuff Equipment Pvt. Ltd., Mumbai (Model - HC B5) was used for proper mixing of the dry as well as wet ingredients and also for preparation of milk chocolate.

In the prepared product the physico-chemical characteristic were analysed in terms of its moisture (IS: 1964), fat, protein, sugar (IS: 1981), ash and acidity (AOAC 1975) and water activity (Using AQUALAB Wateractivity meter, Model no. 4TE) according to the mentioned standard procedure.

\section{Milk chocolate preparation}

The pre-weigh ingredients (SMP, Sugar, Cocoa powder) were properly mixed in planetary mixer at $300-350 \mathrm{rpm}$. After proper mixing, cocoa butter $\left(38-40^{\circ} \mathrm{C}\right)$ was added and contents were mixed for 1.30-2 hours, for proper mixing of the ingredients and flavour development. This step imitated commercial conching process to prepare a smoother and silkier chocolate. When ingredients were 
properly mixed and form a paste like structure, the mix was poured in mould of desired shape and kept at refrigeration temperature. After 30 minutes, the moulded product was kept out and packed in aluminium foil to avoid contamination of chocolate. Figure 8 shows the flow diagram for milk chocolate preparation.

\section{Experiment design}

The preliminary experiment showed that the level of above mentioned ingredients and particle size of ingredients are the most critical factor for preparation of milk chocolate. On the basis of preliminary trials, the upper and lower level of ingredients was selected. Central Composite Rotatable Design (CCRD), for four variables of product was adopted to optimize the level of ingredients and to elucidate the effect of these ingredients on the sensory properties. From response surface methodology, 30 runs were obtained in which 6 replicates were at centre point. The range of ingredient for SMP, icing sugar, cocoa powder and cocoa butter was- 16 to 20 , 39 to 43,8 to 12 and 27.5 to 33 , percent respectively. The experiment design in actual values of variables is shown in table 1 while the coded and uncoded forms of the design matrix for the experiments are presented in table 2. The data were analysed, and a prediction equation was generated for each response. The generalized form of the polynomial equation is given below.

Equation; $\mathrm{Y}=\mathrm{B}_{0}+\mathrm{B}_{1} \mathrm{X}_{1}+\mathrm{B}_{2} \mathrm{X}_{2}+\mathrm{B}_{3} \mathrm{X}_{3}+\mathrm{B}_{4}$ $\mathrm{X}_{4}+\mathrm{B}_{12} \mathrm{X}_{1} \mathrm{X}_{2}+\mathrm{B}_{13} \mathrm{X}_{1} \mathrm{X}_{3}+\mathrm{B}_{14} \mathrm{X}_{1} \mathrm{X}_{4}+\mathrm{B}_{23}$ $\mathrm{X}_{2} \mathrm{X}_{3}+\mathrm{B}_{24} \mathrm{X}_{2} \mathrm{X}_{4}+\mathrm{B}_{34} \mathrm{X}_{3} \mathrm{X}_{4}+\mathrm{B}_{11} \mathrm{X}_{1}^{2}+\mathrm{B}_{22}$ $\mathrm{X}_{2}^{2}+\mathrm{B}_{33} \mathrm{X} 3^{2}+\mathrm{B}_{44} \mathrm{X}_{4}^{2}$

Where,

$\mathrm{Y}=$ Sensory or analytical response

$\mathrm{X}=$ Independent variables

$\mathrm{B}=$ Regression coefficient.

\section{Sensory evaluation}

A sensory panel consisting of 8 trained panellists drawn from the faculty of the college of Dairy Science and Technology (GADVASU), Ludhiana, evaluated the samples of the milk chocolate. The panellists were served with 8-10 gram of the tempered milk chocolate bites. These samples were evaluated for various attributes, namely Appearance, flavour, mouth feel, melting, texture, sweetness and overall acceptability using a nine-point hedonic scale rating (Amerine et al., 1965). This method does not, of course, reflect actual consumer perception, but it does strongly indicate attributes which a good quality product should possess.

\section{Results and Discussion}

\section{Colour of the milk chocolate}

The colour scores of the milk chocolate were in the range of $7.12-8.1$ (Table 3). The partial coefficient of the regression model showed that the skim milk powder had a negative significant effect on the colour of the milk chocolate at linear level. The negative sign of linear term means by increasing the level of skim milk powder the colour score of the milk chocolate decreased. Similar negative effect of milk powder and guava powder was found by Mishra et al., 2016 on colour of guava milk chocolate. Amitraj et al., (2015) also found the negative effect of SMP on colour of low-fat chhana based dairy spread. However, cocoa powder; had a positive significant effect on the colour score of the milk chocolate at linear level $(\mathrm{p}<0.05)$. The positive sign of the partial coefficient indicated that with an increase in the level of cocoa powder there was increase in the colour score. Similar finding were reported by Rathor et al., (2016) wherein increased level of banana and milk powder had a negative effect on the colour and increased levels of 
cocoa powder exhibited a positive effect in banana chocolate.

The response surface graph in figure 1a shows that with increased level of SMP the colour score decreases while the graph between cocoa powder and cocoa butter (Fig. 1b) shows that with increased level of cocoa powder, the colour score of the milk chocolate decreased.

\section{Flavour of the milk chocolate}

The flavour scores of the milk chocolate were in the range of 6.7-7.92 (Table 3). The partial coefficients of regression models indicated that the cocoa butter had a significant effect on the flavour score of milk chocolate at linear level $(p<0.01)$. This means by increasing the amount of cocoa butter, there was improvement in the flavour of the milk chocolate. This seems to hold true as well, as butter is the main ingredients which carries flavour of the chocolate. Skim milk powder was another important ingredient had a significant positive effect on flavour of the milk chocolate at the interactive level with sugar $(\mathrm{p}<0.01)$. However, with cocoa powder $(\mathrm{p}<0.05)$ and cocoa butter $(\mathrm{p}<0.01)$ had a significant negative effect.

Similarly Kulkarni et al., (2012) found the same result on flavour of jaggery based nuggets at interaction level. The response surface graph for SMP and sugar (Fig. 2a) showed that there was improvement in the flavour of the milk chocolate when SMP level was increased. Rathor et al., (2016) reported that the flavour score increases by increasing skim milk powder with banana at interaction level in banana chocolate. The graph for SMP and cocoa powder (Fig. 2b) shows that the flavour scores of the milk chocolate decreased when SMP and cocoa powder increased. In a similar manner, Rathor et al., (2016) also found the same effect on flavour of banana chocolate.

\section{Mouth feel of the milk chocolate}

Mouthfeel scores of the milk chocolate ranged from 6 to 8.25 (Table 3). The partial coefficients of regression models indicated that cocoa powder $(\mathrm{p}<0.05)$ and cocoa butter $(\mathrm{p}<0.01)$ had a significant effect on the mouth feel of the milk chocolate (Table 4). The positive sign of both the ingredients at linear level expressed, the mouth feel of chocolate, which increased by increasing both the above mentioned ingredients. Similarly the effect of cocoa powder on mouth feel was observed in guava milk chocolate (Mishra et al., 2016). Also, the effect of cocoa butter was same as, higher fat content in the product gave more smoothness to the product, thus improving the mouth feel as increasing fat content is related to a richer mouth feel, faster melting rate and thus result in giving smoother mouthfeel. Talbot et al., 2005 in their research also found the cocoa butter and milk fat in chocolate at increased level reflecting the same positive effect on mouth feel. The response surface graph (Fig. 3) shows that the mouthfeel score of milk chocolate increases as cocoa butter level increases in milk chocolate preparation.

\section{Melting of the milk chocolate}

Melting scores of the milk chocolate were in the range of 6.6 - 7.95 (Table 3). The partial coefficients of regression models indicated cocoa powder $(\mathrm{p}<0.01)$ and cocoa butter $(p<0.01)$ had a significant positive effect on the melting of the milk chocolate at the linear level (Table 4). As cocoa butter have property to melt at body temperature and people enjoy its taste as it melts in the mouth. In the same manner more amount of butter has the property to melt the chocolate in the mouth easily which increased the characteristic of melting and lowered the level of cocoa butter, kept the chocolate to harder stage. From the response surface graph (Fig. 4) it was shown that by increasing cocoa butter and cocoa powder, melting characteristics of the milk 
chocolate improved. Afoakwa et al., (2008) conducted meltability using Differential scanning calorimetry, concluded in their research that dark chocolate having low fat content melts at high temperature and having more fat content melts at lower temperature (body temperature), thus improve the melting characteristics of chocolate.

Table.1 Levels of ingredients used in central composite rotatable design for milk chocolate

\begin{tabular}{|l|c|c|c|c|c|}
\hline \multirow{2}{*}{} & \multicolumn{6}{|c|}{ Levels of ingredients } \\
\cline { 2 - 6 } & $-\alpha$ & -1 & 0 & +1 & $+\alpha$ \\
\hline SMP & 14 & 16 & 18 & 20 & 22 \\
\hline Sugar & 37 & 39 & 41 & 43 & 45 \\
\hline C. powder & 6 & 8 & 10 & 12 & 14 \\
\hline C. butter & 24.75 & 27.5 & 30.25 & 33 & 35.75 \\
\hline
\end{tabular}

Table.2 Full experimental design for optimization experiments for developing milk chocolate using response surface methodology (ingredients in gram)

\begin{tabular}{|l|c|c|c|c|c|c|c|c|}
\hline Experiment No. & \multicolumn{9}{|c|}{ Coded values } & \multicolumn{4}{c|}{ Uncoded values } \\
\hline & SMP & Sugar & C. Powder & C. butter & SMP & Sugar & C. Powder & C. butter \\
\hline 1 & -1 & -1 & 1 & -1 & 16 & 39 & 12 & 27.5 \\
\hline 2 & 0 & 0 & 0 & 0 & 18 & 41 & 10 & 30.25 \\
\hline 3 & 0 & 0 & 0 & 2 & 18 & 41 & 10 & 35.75 \\
\hline 4 & -1 & 1 & 1 & -1 & 16 & 43 & 12 & 27.5 \\
\hline 5 & 0 & 0 & 0 & -2 & 18 & 41 & 10 & 24.75 \\
\hline 6 & 0 & -2 & 0 & 0 & 18 & 37 & 10 & 30.25 \\
\hline 7 & 0 & 0 & 0 & 0 & 18 & 41 & 10 & 30.25 \\
\hline 8 & 1 & 1 & -1 & -1 & 20 & 43 & 8 & 27.5 \\
\hline 9 & 0 & 0 & 0 & 0 & 18 & 41 & 10 & 30.25 \\
\hline 10 & 1 & 1 & 1 & 1 & 20 & 43 & 12 & 33 \\
\hline 11 & -1 & 1 & -1 & -1 & 16 & 43 & 8 & 27.5 \\
\hline 12 & 1 & -1 & -1 & 1 & 20 & 39 & 8 & 33 \\
\hline 13 & 1 & -1 & 1 & -1 & 20 & 39 & 12 & 27.5 \\
\hline 14 & 0 & 2 & 0 & 0 & 18 & 45 & 10 & 30.25 \\
\hline 15 & -1 & 1 & -1 & 1 & 16 & 43 & 8 & 33 \\
\hline 16 & 0 & 0 & -2 & 0 & 18 & 41 & 6 & 30.25 \\
\hline 17 & 0 & 0 & 0 & 0 & 18 & 41 & 10 & 30.25 \\
\hline 18 & -1 & -1 & -1 & 1 & 16 & 39 & 8 & 33 \\
\hline 19 & -2 & 0 & 0 & 0 & 14 & 41 & 10 & 30.25 \\
\hline 20 & 0 & 0 & 2 & 0 & 18 & 41 & 14 & 30.25 \\
\hline 21 & 1 & -1 & -1 & 1 & 20 & 39 & 8 & 27.5 \\
\hline 22 & -1 & -1 & 1 & 0 & 16 & 39 & 12 & 33 \\
\hline 23 & 0 & 0 & 0 & 0 & 18 & 41 & 10 & 30.25 \\
\hline 24 & 1 & -1 & 1 & 1 & 20 & 39 & 12 & 33 \\
\hline 25 & 0 & 0 & 0 & 0 & 18 & 41 & 10 & 30.25 \\
\hline 26 & -1 & 1 & 1 & 1 & 16 & 43 & 12 & 33 \\
\hline 27 & 2 & 0 & 0 & 0 & 22 & 41 & 10 & 30.25 \\
\hline 28 & -1 & -1 & -1 & -1 & 16 & 39 & 8 & 27.5 \\
\hline 29 & 1 & 1 & 1 & -1 & 20 & 43 & 12 & 27.5 \\
\hline 30 & 1 & 1 & -1 & 1 & 20 & 43 & 8 & 33 \\
\hline
\end{tabular}


Table.3 Sensory score of milk chocolate prepared during optimization studies

\begin{tabular}{|l|l|l|l|l|l|l|l|}
\hline $\begin{array}{l}\text { Experiment } \\
\text { number }\end{array}$ & Colour & Flavour & Mouthfeel & Melting & Texture & Sweetness & OA \\
\hline 1 & 7.77 & 7.35 & 7.2 & 7.35 & 7.4 & 7.7 & 7 \\
\hline 2 & 7.8 & 7.4 & 7.15 & 7.15 & 6.9 & 7.75 & 7.2 \\
\hline 3 & 7.65 & 7.3 & $\mathbf{8 . 2 5}$ & 7.03 & 6.95 & 7.375 & 7.1 \\
\hline 4 & 8.05 & $\mathbf{6 . 7}$ & 6.6 & 6.65 & 6.8 & 6.9 & 6.7 \\
\hline 5 & 7.9 & 6.8 & 6.5 & $\mathbf{6 . 6}$ & 7.15 & 6.7 & 6.7 \\
\hline 6 & 7.85 & 7.2 & 7.2 & 7 & 7.5 & 7.3 & 7.35 \\
\hline 7 & 7.7 & 7.4 & 7.3 & 7.1 & 7.125 & 7.2 & 7.2 \\
\hline 8 & 7.5 & 7.45 & 6.7 & 7 & 7 & $\mathbf{6 . 3}$ & 6.9 \\
\hline 9 & 7.61 & 7 & 7.225 & 7.48 & 7.35 & 7.45 & 7.6 \\
\hline 10 & 7.7 & 7.3 & 7.7 & 7.65 & 7.55 & 7.3 & 7.6 \\
\hline 11 & 7.4 & $\mathbf{6 . 7}$ & $\mathbf{6}$ & 6.7 & 6.6 & 6.8 & 6.7 \\
\hline 12 & 7.6 & 7.43 & 7.1 & 7.4 & 7.5 & 7.2 & 7.55 \\
\hline 13 & 7.68 & 6.98 & 7.1 & 6.8 & 7.2 & 7.6 & 7.1 \\
\hline 14 & 7.7 & 7.25 & 7.1 & 6.9 & 7.5 & 7 & 7.3 \\
\hline 15 & 7.65 & 7.15 & 7.2 & 6.8 & $\mathbf{6 . 5}$ & 7.25 & 7.1 \\
\hline 16 & 7.58 & 7.1 & 6.9 & 6.9 & 6.7 & 6.7 & 6.6 \\
\hline 17 & 7.53 & 7.4 & 7.5 & 7.25 & 7.1 & 7.5 & 7.4 \\
\hline 18 & 7.85 & 7.85 & 7.175 & 7.1 & 6.65 & 7.3 & 7.25 \\
\hline 19 & 7.9 & 7.25 & 7.025 & 6.8 & 6.8 & 7.5 & 7 \\
\hline 20 & $\mathbf{8 . 1}$ & 7.3 & 7.475 & 7.9 & 7.8 & 7.6 & 7.6 \\
\hline 21 & 7.25 & 7.7 & 7.25 & 7.35 & 7.4 & 7.525 & 7.3 \\
\hline 22 & 8.08 & $\mathbf{7 . 9 2 5}$ & 7.1 & $\mathbf{7 . 9 5}$ & $\mathbf{8 . 0 5}$ & 7.625 & $\mathbf{7 . 9}$ \\
\hline 23 & 7.65 & 7.25 & 6.8 & 7.2 & 6.9 & 7.5 & 7.4 \\
\hline 24 & 7.18 & 6.8 & 7.8 & 7.6 & 7.125 & $\mathbf{7 . 7}$ & 7.45 \\
\hline 25 & 7.65 & 7.3 & 7.125 & 7.5 & 7.175 & 7.425 & 7.4 \\
\hline 26 & 8.02 & 7.4 & 7.6 & 7.45 & 7.75 & 7.425 & 7.6 \\
\hline 27 & $\mathbf{7 . 1 2}$ & 7.3 & 6.8 & 6.9 & 7.25 & 6.8 & 7.2 \\
\hline 28 & 7.69 & 6.9 & 6.7 & 6.8 & 6.8 & 6.6 & $\mathbf{6 . 5 5}$ \\
\hline 29 & 7.82 & 7.6 & 6.8 & 7 & 7 & 6.8 & 7.25 \\
\hline 30 & 7.75 & 7.45 & 7.475 & 7.4 & 7.4 & 7.1 & 7.3 \\
\hline 5605 & & 1.95 & & \\
\hline
\end{tabular}

Scores in bold numeric represent the maximum and minimum value for each particular parameter. 
Table.4 Regression coefficient for sensory responses and their level of significance

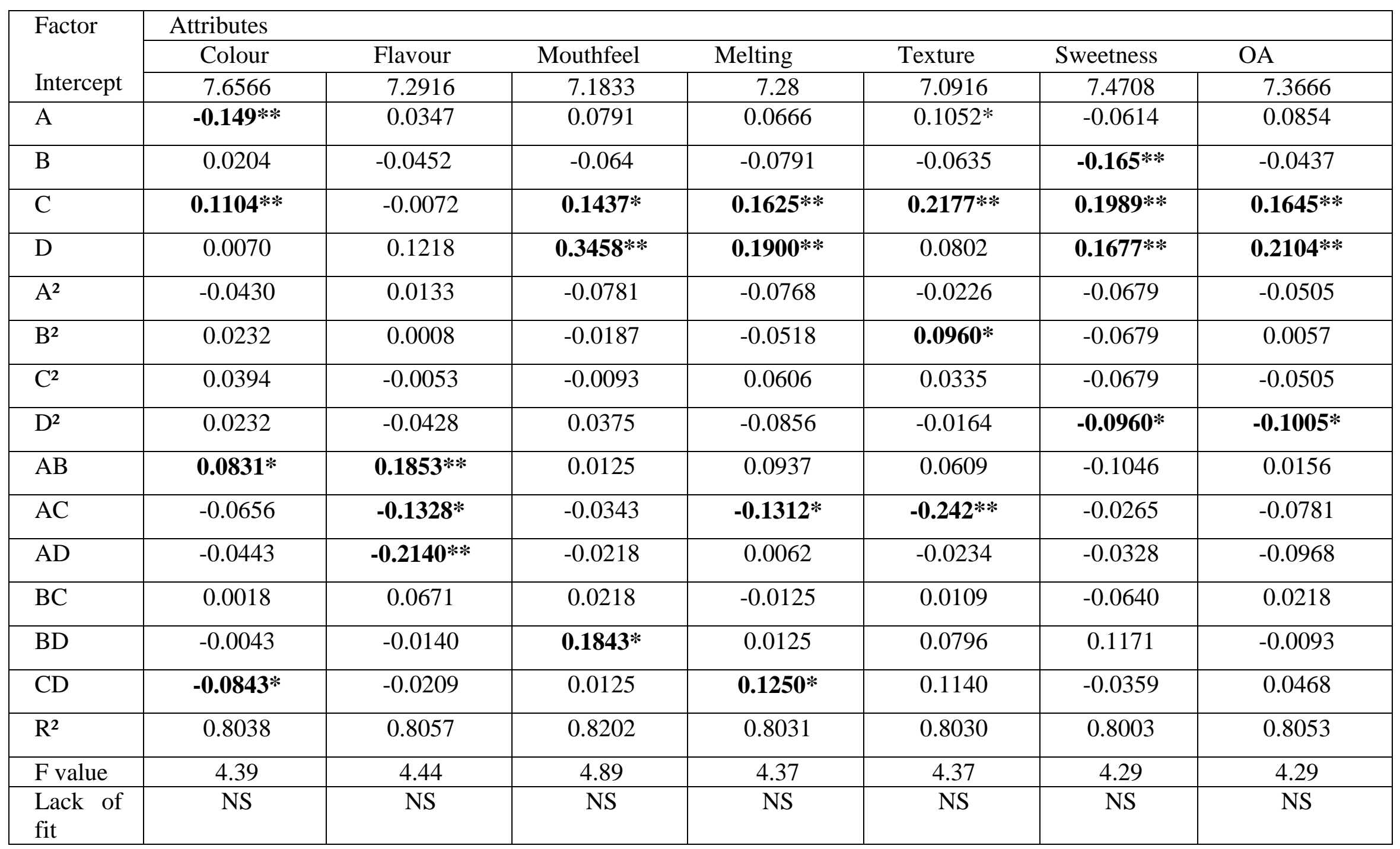

Significance level $=* * \mathrm{p}<0.01, * \mathrm{p}<0.05$

A-SMP, B- Sugar, C- Cocoa powder and D- Cocoa butter. 
Fig.1a Represents the Interaction of SMP and sugar on colour score of milk chocolate, whereas Fig.1b represents the Interaction of cocoa powder and cocoa butter on colour score, Fig.2a shows the Interaction of SMP and sugar on Flavour score of milk chocolate and Fig.2b show the interaction of SMP and cocoa powder on flavour score of milk chocolate

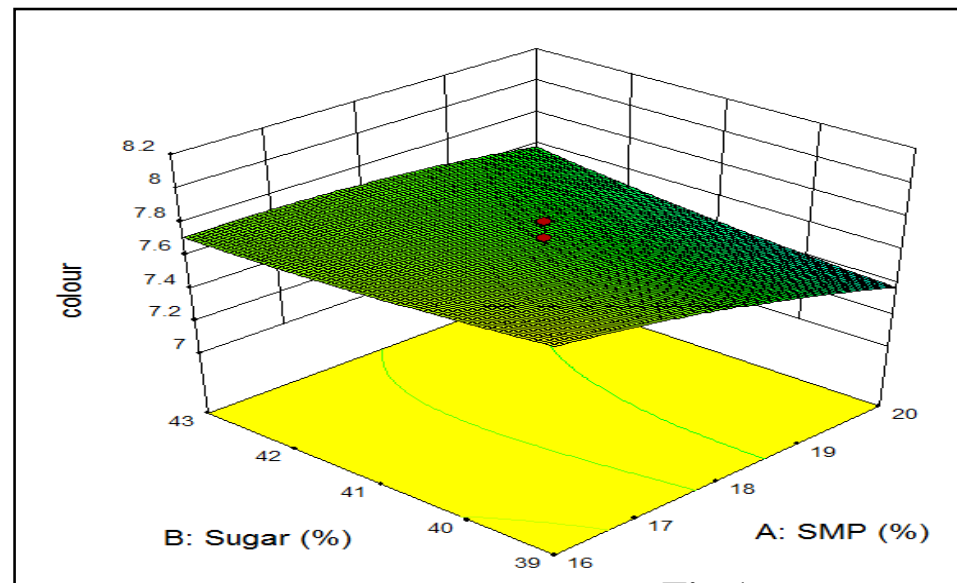

Fig $1 \mathrm{a}$

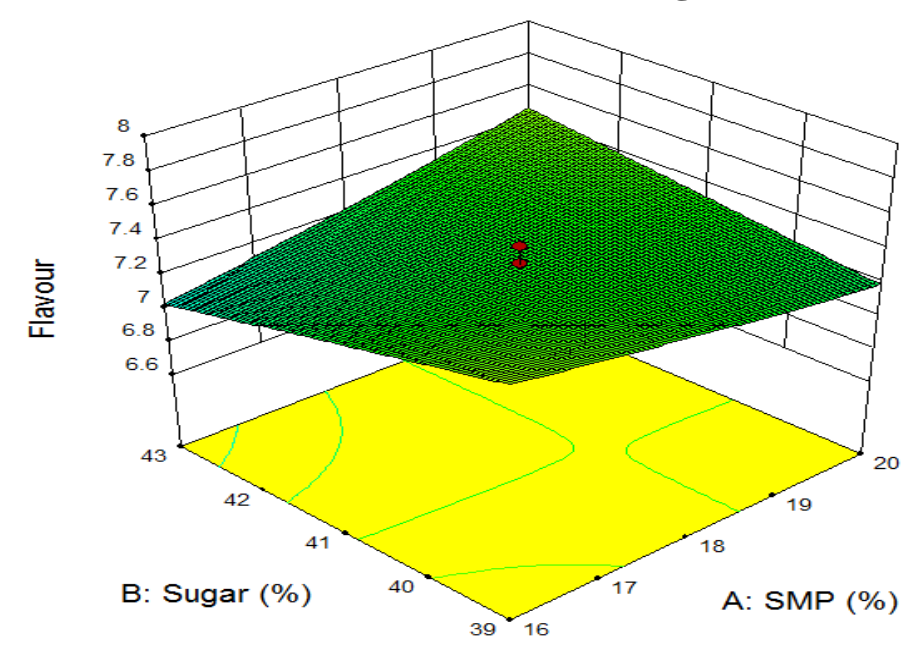

Fig 2a

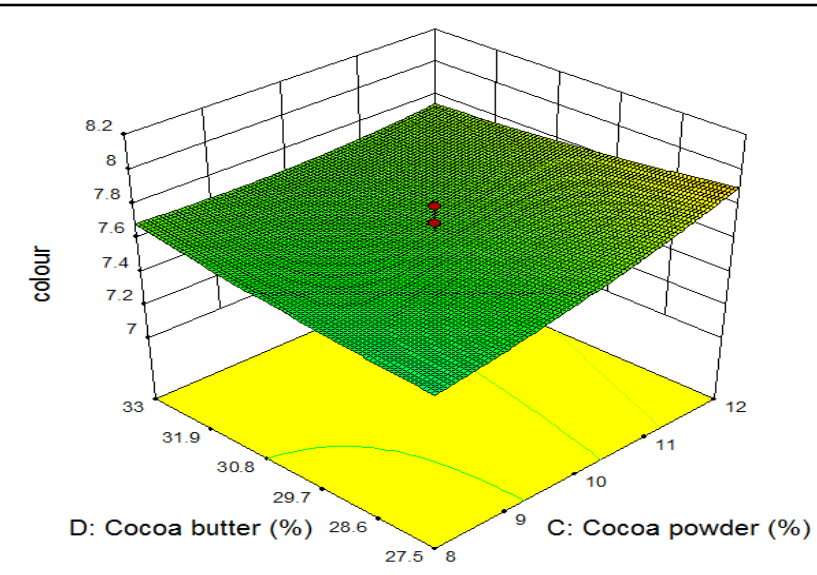

Fig 1b

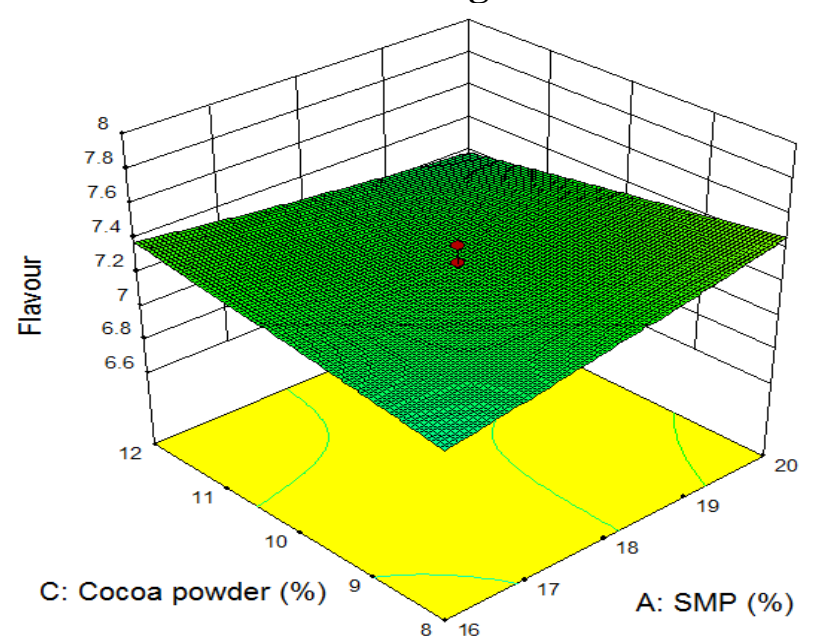

Fig $2 b$ 
Table.5 Model Verification using t-test

\begin{tabular}{|l|c|c|c|c|c|c|c|}
\hline Constraints & Appearance & Flavour & $\begin{array}{l}\text { Mouth } \\
\text { feel }\end{array}$ & Melting & Texture & Sweetness & $\begin{array}{l}\text { Overall } \\
\text { acceptability }\end{array}$ \\
\hline $\begin{array}{l}\text { Predicted } \\
\text { solution }\end{array}$ & 7.99 & 7.84 & 7.46 & 7.83 & 7.78 & 7.63 & 7.72 \\
\hline $\begin{array}{l}\text { Observed } \\
\text { value (O) }\end{array}$ & 7.94 & 7.58 & 7.51 & 7.84 & 7.85 & 7.89 & 7.8 \\
\hline
\end{tabular}

$P(T<=t)$ two-tail $=0.73$, $t$ Critical two-tail $=2.22$

The highlightened value signifies NS difference between predicted and observed values. As calculated $\mathrm{t}(0.73)$ is less than table t value (2.22).

Table.6 Physico-chemical parameters of optimized milk chocolate

\begin{tabular}{|c|c|c|}
\hline Sr. No. & Parameter & Value \\
\hline \multicolumn{3}{|c|}{ Sensory scores } \\
\hline 1. & Colour & $7.69 \pm 0.23$ \\
\hline 2. & Flavour & $7.26 \pm 0.29$ \\
\hline 3. & Mouthfeel & $7.12 \pm 0.42$ \\
\hline 4. & Melting & $7.15 \pm 0.35$ \\
\hline 5. & Texture & $7.16 \pm 0.37$ \\
\hline 6. & Sweetness & $7.23 \pm 0.37$ \\
\hline 7. & OA & $7.21 \pm 0.32$ \\
\hline \multicolumn{3}{|c|}{ Instrumental Colour Measurement } \\
\hline 8. & $\mathrm{~L}^{*}$ & $41.88 \pm 1.4$ \\
\hline 9. & $\mathrm{a}^{*}$ & $6.52 \pm 0.16$ \\
\hline 10. & $\mathrm{~b}^{*}$ & $5.8 \pm 0.16$ \\
\hline \multicolumn{3}{|c|}{ Texture profile analysis } \\
\hline 11. & Hardness & $17.44 \pm 0.036 \mathrm{~N}$ \\
\hline 12. & Stringiness & $15.53 \pm 0.10 \mathrm{~mm}$ \\
\hline 13. & Gumminess & $5.44 \pm 0.02 \mathrm{~N}$ \\
\hline 14. & Cohesiveness & $0.33 \pm 0.004$ \\
\hline 15. & Resilience & $1.54 \pm 0.012$ \\
\hline \multicolumn{3}{|c|}{ Microbiological count } \\
\hline 16. & SPC & $3000 \mathrm{cfu} / \mathrm{ml}$ \\
\hline 17. & Yeast \& mold & Nil \\
\hline 18. & Coliform & Nil \\
\hline \multicolumn{3}{|c|}{ Proximate Analysis } \\
\hline 19. & Water activity & $0.345 \pm 0.0032$ \\
\hline 20. & Moisture (per cent) & $1.77 \pm 0.008$ \\
\hline 21 & Protein (per cent) & $11.58 \pm 0.36$ \\
\hline 22 & Fat (per cent) & $32.24 \pm 0.18$ \\
\hline 23. & Total Sugar (per cent) & $51.03 \pm 1.5$ \\
\hline 24. & Acidity (per cent lactic acid) & $0.42 \pm 0.02$ \\
\hline 25. & Ash (per cent) & $1.76 \pm 0.04$ \\
\hline
\end{tabular}


Fig.3 represents the Interactive effect of sugar and cocoa butter on mouthfeel score of milk chocolate, Fig.4 represents the Interactive effect of cocoa powder and cocoa butter on melting score of milk chocolate, whereas Fig.5 shows the Interaction of SMP and cocoa powder on texture, and Fig.6 and Fig.7 shows the interaction of sugar and cocoa butter on sweetness score and cocoa powder and cocoa butter on overall acceptability score of milk chocolate, respectively.

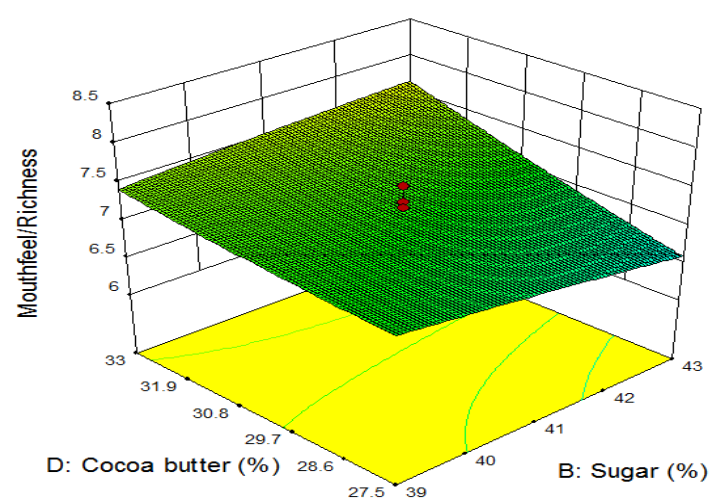

Fig 3

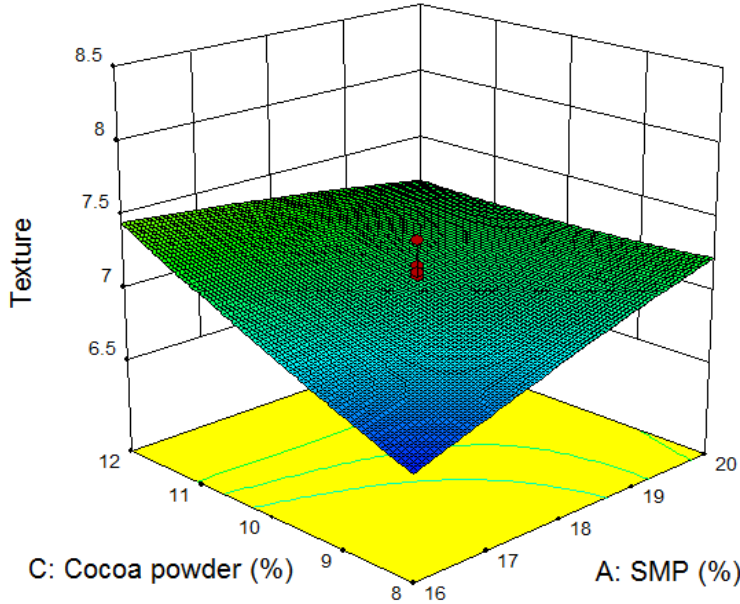

Fig 5

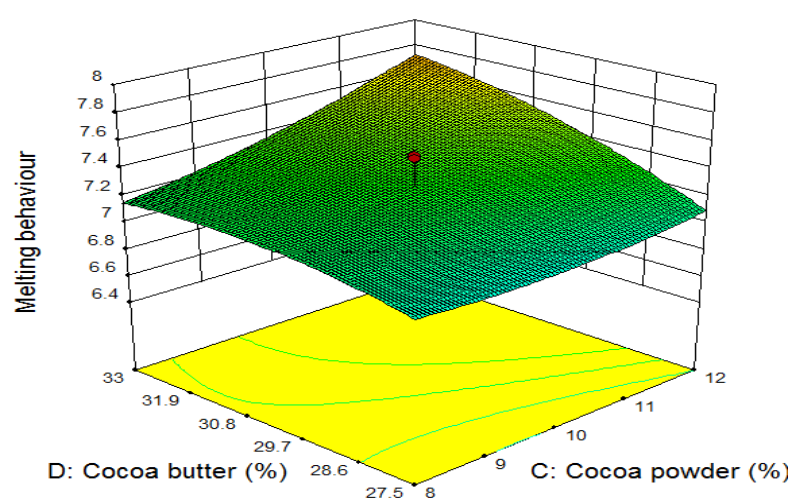

Fig 4

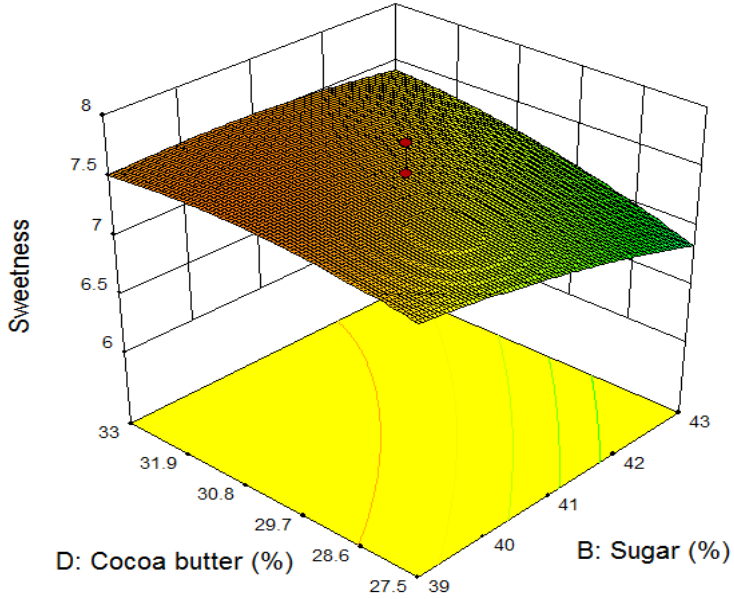

Fig 6

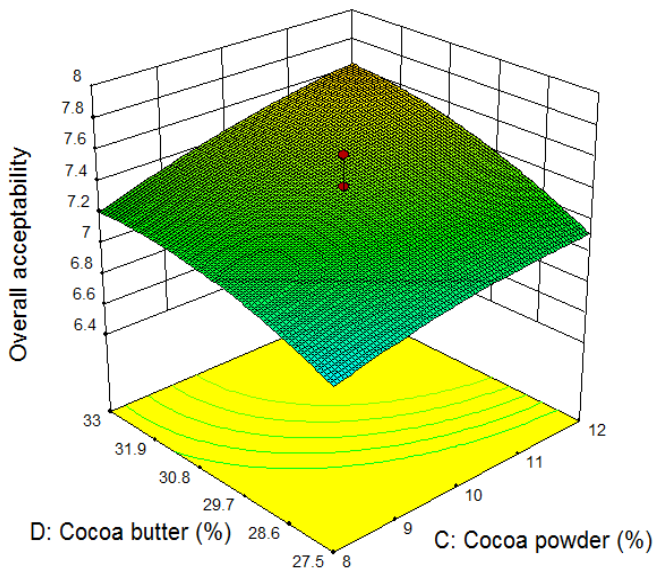

Fig 7 
Fig.8 Flow diagram of milk chocolate preparation

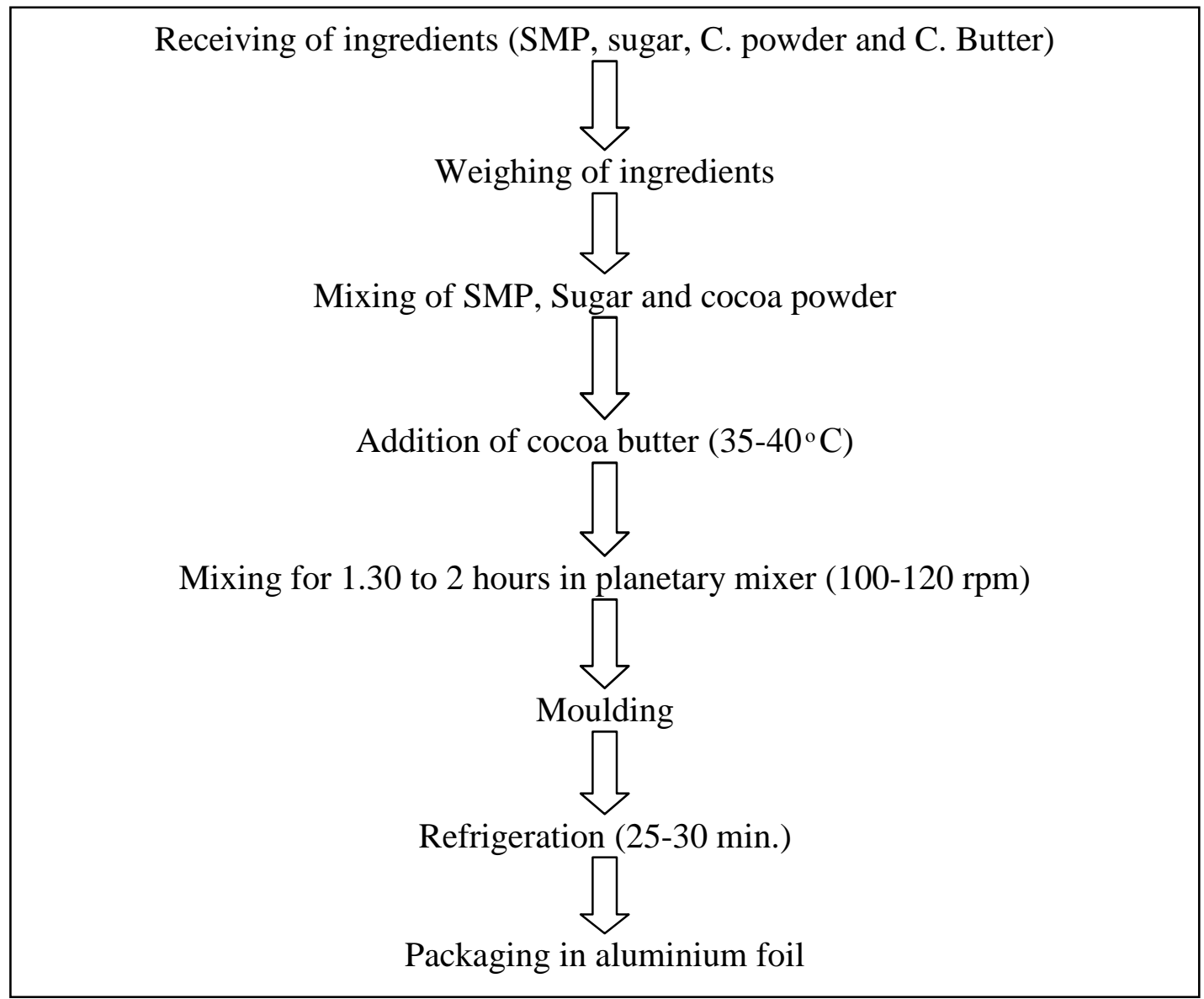

\section{Texture of the milk chocolate}

Texture scores of the milk chocolate were ranged from 6.50 to 8.05 (Table 3). The partial coefficients of regression models showed that SMP had a significant positive effect on the texture of the milk chocolate at the linear level $(p<0.5)$. Cocoa powder was another ingredient that also had a significant effect on the texture of the milk chocolate at the linear level $(\mathrm{p}<0.1)$. Same effect was found by Mishra et al., (2016) in guava chocolate. However at interaction level, SMP and cocoa powder effect texture of the milk chocolate acted inversely. The response surface graph (Fig. 5) shows that SMP and cocoa powder decreased the texture score of the milk chocolate with increased level. The regression coefficient (Table 4) show that, Sugar also a positive and significant effect on the texture of the milk chocolate at quadratic level $(\mathrm{p}<0.05)$, indicating increased sugar level always improves the texture of milk chocolate, being a bulking agent. Interaction of cocoa powder with skim milk powder had a significant negative impact on texture of milk chocolate $(p<0.05) \quad$ (Table 4). The similar negative effect of SMP and cocoa powder was also found by Garud et al., (2012) in their research on jaggery chocolate w.r.t texture score.

\section{Sweetness of the milk chocolate}

Sweetness scores of the milk chocolate ranged from 6.3 to 7.7 (Table 3). The partial 
coefficients of regression models (Table 4) showed that the sugar had a significant negative effect on milk chocolate at linear level $(\mathrm{p}<0.01)$, the negative sign indicate that the increased level of sugar decrease the sweetness score for milk chocolate. Jayabalan et al., (2013) also found the similar results for taste of Aloe Vera jam, wherein they found that the sensory value of taste increased with increase in aloe vera juice and sugar up to certain level thereafter sensory score decreased with further increase in aloe vera juice and sugar. Cocoa powder and cocoa butter were another ingredients which had a significant positive effect on the sweetness of the milk chocolate at linear level $(p<0.01)$. Similarly, in case of a chocolate-flavored peanut beverage (CFPB) optimized by Chompreeda et al., (1989), it was reported that sweetness was influenced by both sugar and cocoa powder. The response surface graph for sweetness of milk chocolate (Fig. 6) shows that the sweetness score of milk chocolate increased with increased level of cocoa butter whereas inverse relation was observed with respect to sugar addition. At quadratic level $(\mathrm{p}<0.05)$, cocoa butter also had a significant effect on sweetness of the product, the negative sign in regression coefficient table indicates that the sweetness score decreased by either increased or decreased level of cocoa butter from centre point. In a similar manner, Kulkarni et al., (2012), found the same effect at quadratic level in jaggery based nuggets wherein sensory scores were influenced by increased or decreased level of cocoa butter from central point.

\section{Overall acceptability of the milk chocolate}

Overall acceptability scores of the milk chocolate were in the range of 6.55-7.9 (Table $3)$. The partial coefficients of regression models (Table 4) indicated that cocoa powder and butter had a positive significant effect on the overall acceptability of the milk chocolate at linear level $(\mathrm{p}<0.01)$. Similar results were also obtained by Garud et al., (2012) in their research on jaggery chocolate; wherein they found that the overall acceptability score of jaggery chocolate improved with the increased level cocoa butter. Cocoa butter at quadratic level $(\mathrm{p}<0.05)$ also had a significant negative effect on overall acceptability of milk chocolate, the negative sign at quadratic level indicates that the overall acceptability negatively affected by increased or decreased level of cocoa butter from central point. Similar finding were reported by Garud et al., (2012) in jaggery chocolate at quadratic level, Author reported the negative effect of SMP, cocoa powder and cocoa butter in jaggery chocolate at quadratic level. The response surface graph (Fig. 7) shows that cocoa powder and cocoa butter at increased level increased the overall acceptability of the milk chocolate.

The criteria for selecting these responses were based on literature survey which strongly recommended sensory evaluation, which affects the acceptability of the finished product to a great extent. Optimization of results was carried out and the goals were set to arrive at a final recipe formulation. Except over all acceptability, all the responses were taken as range and OA was kept at maximize. From optimization, single solution was obtained that suited the criteria, was selected, and the model verification of the selected solution was done using t-test as shown in table 5. There was least difference between the observed score of milk chocolate and the predicted score by design expert and a nonsignificant difference between these two values was obtained. It was observed from the sensory scores at different levels of ingredients, experiment no. 22 (with composition SMP 16\%, sugar 39\%, cocoa powder $12 \%$ and cocoa butter $33 \%$ ) had the highest score for most of the responses. The optimized results depicted 16, 39, 12 and 33 
per cent of SMP, sugar cocoa butter, and cocoa powder to be used in the formulation to get a desirable milk chocolate with maximum acceptability. The results for optimized chocolate in terms of its physico- chemical analysis have been mentioned in table 6 .

Based on the results of sensory and physical analysis of the milk chocolate formulated using different levels of SMP, Sugar, cocoa powder and cocoa butter, a combination of the ingredients with very good desired results was obtained. Response surface methodology was well suited for evaluating the individual and interaction effect of variables on sensory characteristics of milk chocolate. The optimized formulation, suggested by the design expert package, contained 16\% SMP, $39 \%$ sugar, 12\% Cocoa powder and 33\% Cocoa butter.

\section{References}

Afoakwa, E O., Paterson, A., Fowler, $\mathrm{M}$ and Vieira, J. 2008. Characterization of melting properties in dark chocolates from varying particle size distribution and composition using differential scanning calorimetry. Food Research International. 41(7): 751-757.

Allen, R R., Carson, L., Kwik-Uribe, C., Evans, E M and Erdman, J W. 2008. Daily consumption of a dark chocolate containing flavanols and added sterol esters affects cardiovascular risk factors in a normotensive population with elevated cholesterol. The Journal of nutrition. 138(4): 725-731.

Amerine, M A., Pangborn, R M and Roessler, E B. 1965. Principals of Sensory Valuation of Food. New York: Academic Press.

Amitraj, K., Khamrui, K., Devaraja, H C and Mandal, S. 2015. Optimisation of ingredients for a low-fat, Chhana-based dairy spread using response surface methodology. International Journal of Dairy Technology.

Andres, L C., Shukitt, H B., Galli, R L., Jauregui, O., Lamuela, R R M and Joseph, J A. 2005. Anthocyanins in aged blueberry-fed rats are found centrally and may enhance memory. Nutritional neuroscience. 8(2): 111-120.

AOAC 1975. Official methods of analysis, 12thEdn. Association of Official Analytical Chemists, Washington, DC.

Chompreeda, P., Haruthaithanasan, V., Oupadissakoon, C and Suknak, K. 1989. A research note: Development of a chocolate flavored peanut beverage. Journal of Food Science. 54(5):13591360.

Davison, K., Coates, A M., Buckley, J D., Howe, P R C. 2008. Effect of cocoa flavanols and exercise on cardiometabolic risk factors in overweight and obese subjects. International Journal of Obesity. 32(8): 1289-1296.

Ding, E L., Hutfless, S M., Ding, $X$ and Girotra, S. 2006. Chocolate and prevention of cardiovascular disease: a systematic review. Nutrition \& metabolis. 3(1): 2.

Garud, S R and Lamdande, A G. 2012. Effect of different ingredent levels on texture of jaggery chocolate evaluated by using response surface methodology. Quarterly Journal of Life Sciences. 9(4): 654-655.

Grassi, D., Desideri, G., Croce, G., Pasqualetti, P A O L O., Lippi, C and Ferri, C. 2006. Cocoa and cardiovascular health. The sweet heart protection. Agro Food Industry HiTech. 17: 13-16.

IS: 1224 (Part 1) 1964. Determination of moisture content in burfi. Bureau of Indian Standards. Manak Bhavan, New Delhi. 
IS: SP 18 (Part XI) 1981. Handbook of food analysis. Part XI, Dairy Products. Bureau of Indian Standards. Manak Bhavan, New Delhi.

Jayabalan, K and Karthikeyan, C. 2013. Optimization of ingredients for sensory evaluation of Aloe vera jam preparation using response surface methodology (RSM). International Journal of Engineering Research and Applications. 3(1): 1224-1234.

Jyothi, DPT. 2003. The chocolate story: No clear norms on storage. The Hindu Group of publications.

Kulkarni, N., Kumar, A., Omre, P K and Kumbhar, B K. 2012. Ingredients optimization in jaggery based nuggets with spices using RSM. International Journal of Processing \& Post Harvest Technology. 3 (2): 237-242.

Mishra, D., Kumar, C A., Bhardwaj, R., kumar, P and Yadav, D. 2016. Optimization of Guava Milk Chocolate Using Response Surface Methodology. Biosciences, Biotechnology Research Asia. 13(3): 1715-1723.

Pimentel, F A., Nitzke, J A., Klipel, C B and de Jong, E V. 2010. Chocolate and red wine-A comparison between flavonoids content. Food Chemistry. 120(1): 109112.

Rathor, Y K., Singh, S., Kumar, S and Pandey, R K. 2016. Optimization and Storage Study of Banana Chocolate. International Journal of Agriculture,
Environment and Biotechnology. 9(5): 861-868.

Schinella, G., Mosca, S., CienfuegosJovellanos, E., Pasamar, M Á., Muguerza, B., Ramón, D and Ríos, J L. 2010 Antioxidant properties of polyphenol-rich cocoa products industrially processed. Food Research International. 43(6): 1614-1623.

Shahkhalili, Y., Duruz, E and Acheson, K. 2000. Digestibility of cocoa butter from chocolate in humans: a comparison with corn-oil. European journal of clinical nutrition. 54(2): 120.

Talbot, G. 2005. Cocoa butter and milk fat in chocolate-Geoff Talbot examines this aspect of chocolate production. Confection. 49-51.

Taubert, D., Roesen, R and Schömig, E. 2007. Effect of cocoa and tea intake on blood pressure: a meta-analysis. Archives of internal medicine. 167(7): 626-634.

Vanzani, P., Rossetto, M., De Marco, V., Rigo, A and Scarpa, M. 2011. Efficiency and capacity of antioxidant rich foods in trapping peroxyl radicals: A full evaluation of radical scavenging activity. Food Research International. 44(1): 269-275.

Vauzour, D., Vafeiadou, K., RodriguezMateos, A., Rendeiro, C and Spencer, J P. 2008. The neuroprotective potential of flavonoids: a multiplicity of effects. Genes \& nutrition. 3(3-4): 115-126.

\section{How to cite this article:}

Singh Manpreet, Chawla Rekha, Sunil Khatkar and Singh Sandeep. 2017. Development of Milk Chocolate Using Response Surface Methodology (RSM). Int.J.Curr.Microbiol.App.Sci. 6(6): 2881-2894. doi: https://doi.org/10.20546/ijcmas.2017.606.341 